\title{
Preparation of Poly(Vinyl) Alcohol/Chitosan Hybrid Membranes Doped with Graphene Nanosheets
}

\author{
E. Acurio, L. García-Cruz, V. Montiel, J. Iniesta* \\ Department of Physical Chemistry, University Institute of Electrochemistry, University of Alicante, \\ 99, Apartado de Correos, Alicante, 03080, Spain \\ *Corresponding author. Tel.: (+34) 9659035 36.E-mail: jesus.iniesta@ua.esw
}

\begin{abstract}
The development of ion exchange membrane technology has allowed its introduction in many industrial sectors, such as electrodialysis and electrolysis. Nowadays, membranes are the crucial element in electrochemical energy conversion and storage devices. This work is aimed at examining new eco-friendly membranes materials to improve structural, mechanical, electrical and barrier properties. A simple and ecological synthesis of alkaline anion exchange membranes based on a mixed matrix membrane of chitosan (CS) and poly(vinyl) alcohol (PVA) - CS:PVA polymeric matrix - was developed by using a 50:50 wt. \% ratio. The CS:PVA matrix was modified with variable loadings of graphene pristine sheets (GPH) ranging between 0,5 and $4.0 \mathrm{wt}$. \%. The physico-chemical characterization of each of the membranes prepared was carried out in order to examine the topology, structure, thermal stability, surface chemistry, and water content (WC), as well as the ionic conductivity by using electrochemical impedance spectroscopy (EIS). Results revealed that the incorporation of graphene (GPH) into the CS:PVA polymeric matrix leads to the improvement of the thermal stability, and the ionic conductivity of the pristine polymeric matrix. The loading of $1.0 \mathrm{wt} \%$ of GPH into CS:PVA was optimal in terms of specific ionic conductivity that is related to surface chemistry of the membrane, WC, and slight roughness of the membrane topology. The presence of GPH only provided a slight loss of crystallinity of the memebrane compared to the unmodified CS:PVA membrane, which also resulted in the reduction of water content with moderately GPH loadings. With regard to the ionic conductivity, an almost twofold increase was obtained compared to the pure CS:PVA for an optimal loading of $1.0 \mathrm{wt} . \%$.
\end{abstract}

\section{Keywords}

Chitosan; poly(vinyl) alcohol; cellulose; anionexchange membrane; graphene; carbon materials.

(C) E. Acurio, L. García-Cruz, V. Montiel, J. Iniesta, 2017

\section{Introduction}

An ion exchange membrane generally consists of a polymeric skeleton, on which ions or ionic functional groups of cationic or anionic nature are incorporated into the polymeric backbone, allowing the transport of selectively charged ions $[1,2]$. Ion exchange membranes have played an important role in industry, as well as in daily life, among their applications are, for example, oil refineries for water regeneration purposes, drinking water filters, batteries, electrodialysis, fuel cells, biomedical purifications, and controlled drug administration [3].

From the technological point of view, composition and structure of ionic exchange membranes are the most important aspects to bear in mind. Membrane performance can be considerably enhanced using multi-component materials, i.e., either by blending different polymeric materials or by altering the chemistry of the polymer $[4,5]$ to improve the properties corresponding to strength, ionic conductivity, thermal and chemical stability, and permeability. Moreover, doping or hybridizing the polymeric matrix via sol-gel methods with inorganic [6] and organic [6,7] salts may also enhance membrane performance [8-10]. Particularly, carbonaceous materials are known as additives capable of improving the ionic conductivity, reducing the permeability and increasing the robustness [11-14]. Polymer industry is generally devoted to the synthesis and manufacture of ion exchange membranes dominated by the use of synthetic polymers obtained from non-renewable resources or complex, toxic 


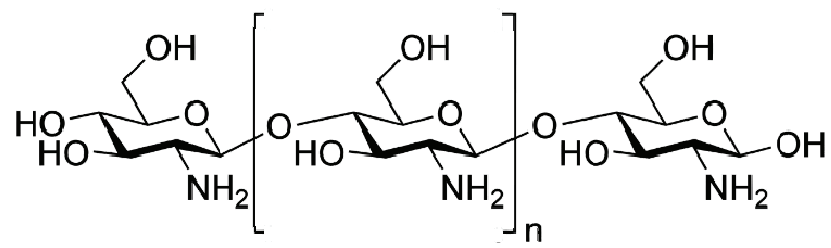

Scheme 1. Chitosan structure

syntheses. However, biodegradable and eco-friendly polymers, such as chitosan (CS) and cellulose (Cell) biopolymers, and polymers like poly(vinyl) alcohol (PVA) and polylactic acid (PLA), among others, are gaining popularity in the synthesis and manufacture of ion exchange membranes for multiple applications [15-19]. Biopolymers have desirable properties in terms of sustainability, low carbon footprint and renewable production [20]. In this regard, CS is an example of biopolymer with low cost and weak cationic polyelectrolyte (with a pKa of ca. 6.5) obtained from natural resources such as molluscs [21] which appeared to have good chemical and physical properties, making it a very good candidate for application in ion exchange membrane [17]. Moreover, CS is a copolymer of glucosamine and $\mathrm{N}$-acetylglucosamine, as shown in Scheme 1. The presence of amino (which provide an ionic character) and hydroxyl groups is also worth noticing [5].

Application of CS-based membranes can be found in diverse areas, such as the pharmaceutical industry, fuel cells, sewage treatment, and food packaging [15]. CS membranes have been produced in various forms: as supports, films, fibers, etc. [22]. The inherent properties of CS as well as its high degree of hydrophobicity allow to work under high temperatures conditions, with interesting applicatios in pervaporation [23].

CS-based membrane properties stand out for its insolubility in most organic solvents, alkalis and water, but solubility in dilute organic acids, such as an acetic acid or formic acid. However, its low mechanical resistance and low electrical conductivity are significant disadvantages that could hinder its use and incorporation into electrochemical devices like solid polymer electrolyte fuel cells or electrochemical reactors with a similar architecture [24]. One of the strategies, most used to obtain CS polymeric matrices with reinforced structure and enhanced thermal and chemical stability, and ionic conductivity, is based on the polymeric blending. PVA, as shown in Scheme 2, is the polymer, most widely used as an additive to be incorporated into the CS matrix because of its high miscibility therein and its solubility in aqueous solutions. However, the physico-chemical properties related to the thermal, chemical, mechanical and electrochemical performances of CS can be also enhanced by incorporating an additive of inorganic nature, for instance, carbon materials [15, 22-24].

The addition of graphene to polymeric matrices has been recently studied in which pristine CS and PVA, and hybrid CS:PVA membranes have been modified by means of the addition of reduced graphene oxide (rGO), providing an increase in tensile strength and at the glass transition temperature $\left(T_{\mathrm{g}}\right)$ [14]. The improvements in ionic conductivity and a reduction in the permeability of alcohols by adding graphene (GPH) or sulfonated graphene (sGPH) have also been demonstrated in other studies [11]. On the other hand, there are papers which highlight an enhanced performance of a polymeric matrix of CS or PVA containing GPH [13] and graphene oxide (GO) $[12,13]$. Such carbon materials form hydrogen bonding with the functional groups of the polymeric backbone, thereby allowing an increase in mechanical properties (tensile strength), thermal stability and ionic conductivity. In addition, these studies have demonstrated the possibility of preparing CS:PVA (10:90 wt. \%) membranes modified with graphene and its derivatives for fuel cells applications. Recently, our group has performed the synthesis of hybrid membranes based on CS:PVA with 50:50 wt. \% ratio doped with graphene oxide [25]. The results showed a more remarkable decrease in permeability of $n$ propanol. Conversely, a slight improvement in the ionic conductivity was obtained, which was mostly attributed to the low electrical conductivity of GO material. Motivated by the ammellioration of the ionic conductivity of CS:PVA blend membranes doped with carbonaceous materials, the present article aims to explore the effect of using variable pristine graphene nanosheets loadings into CS:PVA matrix. Membrane preparation consisted of a mixture of chitosan and polyvinyl alcohol (CS:PVA) in a 50:50 wt. \% ratio. Graphene sheets were incorporated into the polymer matrix in order to explore the improvements of ionic conductivity and thermal and chemical stability of the pristine polymer for its application in electrochemical devices. Pristine and doped CS:PVA membranes were explored by scanning electron microscopy, X-ray diffraction (XRD), thermogravimetric analysis (TGA), X-ray photoelectron spectroscopy (XPS), water

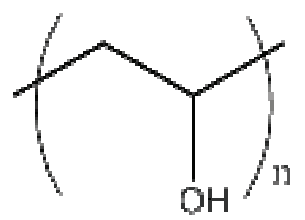

Scheme 2. Structure of poly(vinyl) alcohol 
content and electrochemical impedance spectroscopy. It has been found that 1.0 wt. \% of GPH sheets incorporated into the blend CS:PVA (50:50 wt. \%) is the optimum concentration in terms of ionic conductivity, influenced mainly by a slight rough topography, a decrease in water content, and a more hydrophobic character of the surface membrane.

\section{Methods and Materials}

\section{Chemicals and Solutions}

Chitosan (CS) was obtained from Sigma-Aldrich (Barcelona, Spain) with a molar mass of 310,000 to 375,000 with a degree of deacetylation with not less than $75 \%$ and viscosity ranging between 800-2000 mPas. Polyvinyl alcohol (PVA), $99 \%$ hydrolyzed, was obtained from Sigma-Aldrich with a molar mass between 85,000 and 124,000. Both CS and PVA were used without further purification. Graphene powder with a purity of $99 \%$, (GPH, Graphene Nanopowder in flakes), was obtained from Graphene Supermarket, with an average thickness of $8 \mathrm{~nm}$, a specific surface area of $100 \mathrm{~m}^{2} \cdot \mathrm{g}^{-1}$ and average particle (lateral) of ca. $550 \mathrm{~nm}$. The solutions were prepared using doubly distilled water with a resistivity not less than $18.2 \mathrm{M} \Omega \cdot \mathrm{cm}$. All other chemicals were purchased of the highest available quality and were used without further purification.

\section{Preparation of Hybrid Membranes}

Polymer matrix based on CS:PVA was prepared from a blend of $1.0 \mathrm{wt} \%$ of CS and $4.0 \mathrm{wt} . \%$ of PVA homogeneous solutions in order to reach a polymer mixture of 50:50 weight ratio, as described in our previous work [25]. The polymer blend was stirred for $24 \mathrm{~h}$ and then a certain amount of GPH dispersion in water was added into the polymer mixture to get the desired weight percentage of GPH. Graphene percentages were set at $0.5,1.0,2.0$ and 4.0 wt. \%, respectively. Membranes were named as $\mathrm{GPH}(\mathrm{x}) / \mathrm{CS}: \mathrm{PVA}$, where $\mathrm{x}$ stands for the graphene wt. \%. A pristine CS:PVA membrane was also prepared in the absence of graphene material for comparison purposes.

\section{Physico-Chemical Characterisation of the Hybrid Membranes}

\section{Thickness and Weight of the Membrane}

Once the membrane was completely dry and peeled off the Petri dish, its thickness was measured in at least 5-6 spots over memebrane area, so an average thickness was obtained. Thickness measurements were carried out using a micrometer (Mitutoyo Corp., Kawasaki, Japan) with an accuracy of $0.001 \mathrm{~mm}$. The weight of the dried membranes was also measured at this point in an electronic balance to calculate the density of the membranes. The ion exchange was carried out by immersing the membranes in $1.0 \mathrm{MNaOH}$ for $24 \mathrm{~h}$ and then thoroughly washed with doubly distilled water to remove the $\mathrm{NaOH}$ excess. Finally, the membranes were ready for further characterisation.

\section{Optical and Scanning Electron Microscopy}

Before the morphology analysis, activated membranes were allowed to be dried at room temperature. The dry and clean membranes of CS:PVA and GPH/CS:PVA were observed with optical microscopy (Motic MLC-150C microscope) at different magnification of $\times 4$ and $\times 10$. SEM was used to explore the surface morphology of the synthesized membranes. SEM images were obtained using a HITACHI S-3000N microscope, which works at $30 \mathrm{kV}$ with a Bruker XFlash $3001 \mathrm{X}$-ray detector.

\section{X-ray Photoelectron Spectroscopy, X-ray Diffraction and Thermogravimetry Analysis}

XPS experiments were performed using a K-alpha Thermo Scientific spectrometer using AlKa $(1486.6 \mathrm{eV})$ monochromatic radiation by a double crystal monochromator and focusing an X-ray point with a diameter of $400 \mathrm{~mm}$, to $3 \mathrm{~mA}$ and $12 \mathrm{kV}$. The deconvolution of the XPS spectra was carried out using a Shirley background. XRD diffractograms were collected on a Philips X'Pert PRO MPD diffractometer operating at $45 \mathrm{kV}$ and $40 \mathrm{~mA}$, equipped with a Johansson germanium monochromator which provides $\mathrm{Cu} \mathrm{K} \alpha 1$ radiation $(\lambda=1.5406 \AA)$, and a detector of Pixcel solid angle, with a pitch of $0.05 \mathrm{deg}$.

Thermogravimetric analysis (TGA) was applied to determine the thermal stability and degradation temperature of the different prepared membranes along with the graphene material used as additive for the modification of the pristine blended polymers. A thermal balance DTG-60H (Shimadzu, Japan) was used under air atmosphere. The temperature range studied was between $25-800{ }^{\circ} \mathrm{C}$ with a heating rate of $10{ }^{\circ} \mathrm{C} \min ^{-1}$.

\section{Water Content}

Water content (WC) of the membrane was calculated from the curves obtained from the TGA experiments using equation (1), according to Franck- 
Lacaze et al. [26]. Both masses $m_{1}$ and $m_{2}$ of the membranes correspond to the observed minimums of the differential thermogavimetric spectrum at $T_{1}$ and $T_{2}$, respectively, with $T_{1}$ being the vaporization temperature of water and $T_{2}$ the degradation temperature of the polymer, respectively.

$$
W C(\%)=100\left(1-\frac{m_{2}}{m_{1}}\right) .
$$

\section{Specific Ionic Conductivity}

The electrochemical characterisation of the membranes was performed by electrochemical impedance spectroscopy (EIS). The specific ionic conductivities of the hydroxyl anions through the membrane were performed by the EIS measurements using a two-electrode Swagelok cell type, which consists of a Teflon coating with two cylindrical electrodes of stainless steel with $1.13 \mathrm{~cm}^{2}$. The membrane was placed between both stainless steel disks in its activated $\mathrm{OH}^{-}$and wet form.

The measurements were performed using a micro Autolab equipped with an impedance module FRA at open circuit potential (potentiostatic method). The impedance spectrum was measured over a frequency range between $100 \mathrm{~Hz}$ and $0.1 \mathrm{MHz}$ with an amplitude potential of $0.01 \mathrm{~V}$ at room temperature $\left(25 \pm 1^{\circ} \mathrm{C}\right)$. The specific ionic conductivity $\sigma\left(\mathrm{mS} \mathrm{cm}^{-1}\right)$ was calculated using equation (2),

$$
\sigma=\frac{e}{R A}
$$

where $e$ is the thickness of the membrane in $\mathrm{cm}, R$ is the resistance in ohm of the membrane and $A$ is the area of the membrane in $\mathrm{cm}^{2} . R$ was obtained by the extrapolation of the Nyquist plot - associated with the diffusion control - to real impedance when imaginary $Z$ equals zero.

\section{Results and Discussion}

Topographical Characteristics of the Membranes

Figure 1 depicts SEM images of GPH/CS:PVA membranes with varying content of GPH at $0.5,1.0$, 2.0 and 4.0 wt. \%. Fig. $1 a$ corresponding to the GPH (0.5)/CS:PVA membrane exhibits a heterogeneous morphology with roughness probably attributed to the polymer mixture itself $[27,28]$. An increase in the content of GPH within the polymer structure provides a more homogeneous and smoother surface (Figures $1 b-d$ ). This smoothing of the surface could

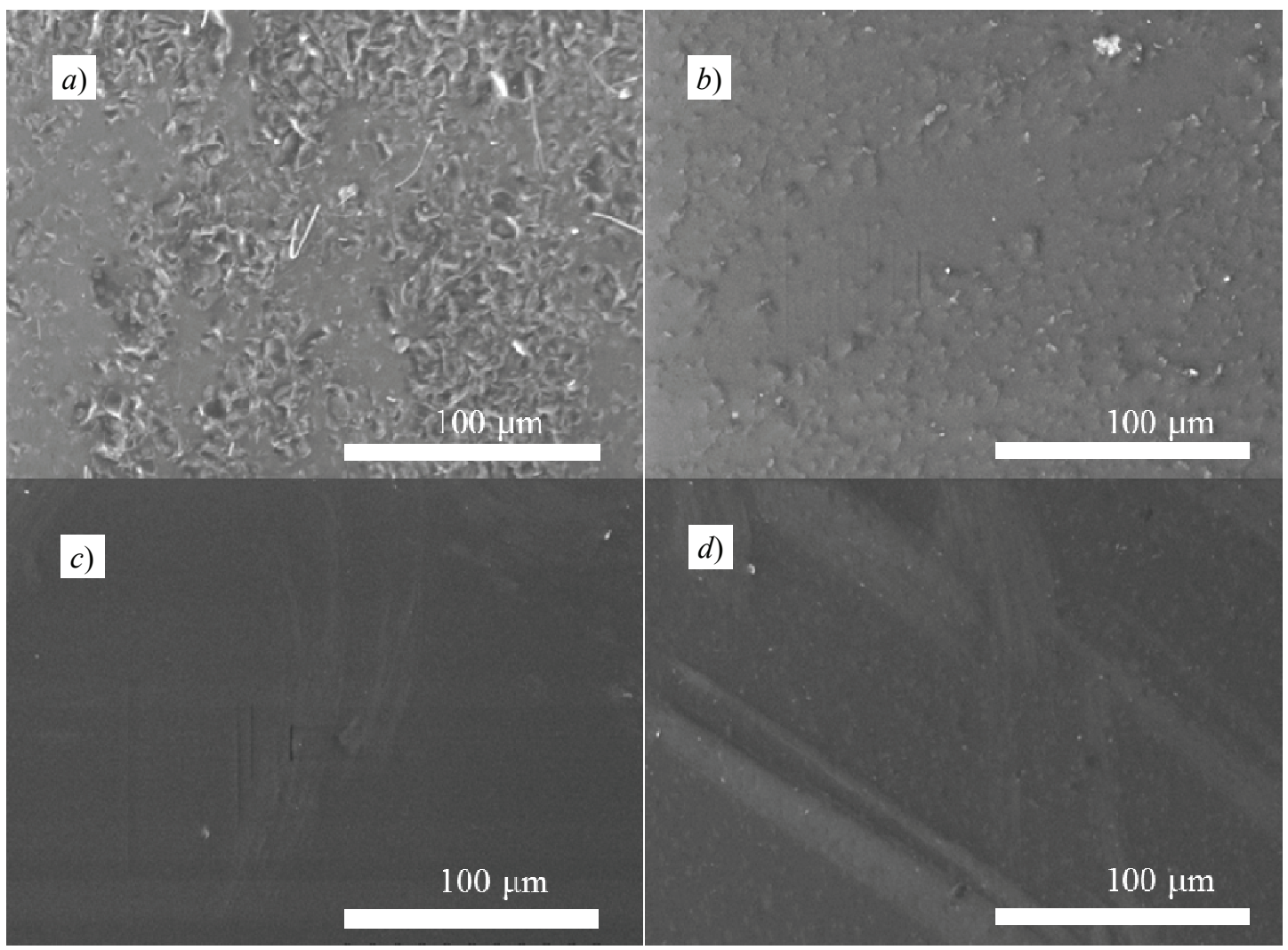

Fig. 1. SEM images of GPH/CS:PVA membranes with 0.5 wt. \% (a), 1.0 wt. \% (b), 2.0 wt. \% (c) and 4.0 wt. \% GPH (d) 


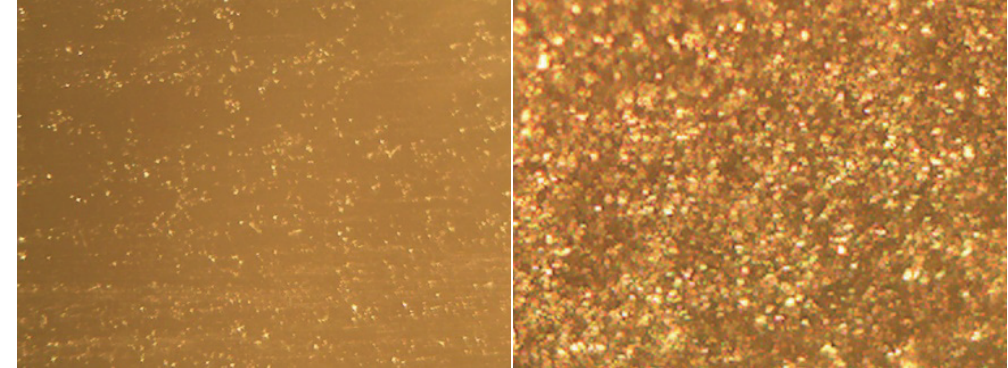

a)

b)

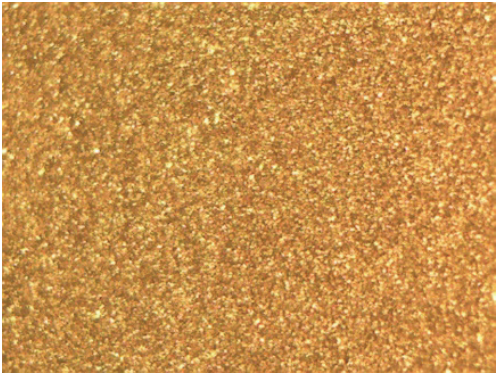

c)

Fig. 2. Optical microscopy images $(\times 10$ zoomed) obtained from the pristine CS:PVA membrane $(a)$ and the GPH/CS:PVA membranes with 0.5 wt. \% (b) and 1.0 wt. \% (c) GPH

be associated with the enhancement of hydrogen bonds interactions between the graphene or graphenic sheets and the hydroxyl and amino functionalised groups being in the blended polymer.

The topographic analysis of the CS:PVA and GPH/CS:PVA membranes with 0.5 and 1.0 wt. \% were also analysed by optical microscope, as shown in Fig. 2.

Figures $2 b$ and $c$ show how GPH sheets are evenly distributed within the polymeric matrix, although with a certain degree of agglomeration. To sum up, the morphology of the different membranes obtained by SEM and optical microscopy reveales that the synthesis method followed in the present work allows an adequate distribution of the GPH within the matrix based on the mixture of the two polymers.

\section{Membrane Crystallinity}

Figure 3 depicts the graphene diffractogram used as an additive. The height and width at half intensity of the main peak of the GPH diffractogram is high and narrow, which reveals a crystalline character of the material. The graphene signal appears at $2 \theta$ of $26.4^{\circ}$ which is attributed to the two dimensional $\left(\begin{array}{lll}0 & 0 & 2\end{array}\right)$ plane of graphene [29]. Furthermore, the spacing value of the graphene sheets was found to be $0.338 \mathrm{~nm}$ equal to that presented in literature $[30,31]$.

Moreover, $L_{\mathrm{c}}$ and $L_{\mathrm{a}}$ parameters were determined by using the Scherrer equation:

$$
L=\frac{K \lambda}{\beta \cos \theta},
$$

where $L$ is the crystal size, $\beta$ stands for the full width at half maximum (FWHM) of a certain peak, $\theta$ is the diffracted angle, $\lambda$ is the radiation wavelength and $K$ is the crystal shape factor that depends on the lattice dimension. For carbon materials, $K$ values of 0.9 and 1.84 are used for calculation of $L_{\mathrm{c}}$ and $L_{\mathrm{a}}$, respectively, as was proposed by Warren and Bodenstein [32].
The $L_{\mathrm{c}}$ value appeared to be $0.432 \mathrm{~nm}$, while the $L_{\mathrm{a}}$ value corresponds to $0.882 \mathrm{~nm}$ exhibiting a nanodimensional plane. Considering that the theoretical interlayer distance between two graphene planes is $0.337 \mathrm{~nm}$, the XRD result suggests the presence of 2.28 layered graphenes.

Figure $4 a$ depicts the XRD plot of pristine CS:PVA membrane displaying a sharp peak at $2 \theta$ between $10-12^{\circ}$, and a second peak at about $18-22^{\circ}$. Figure $4 b$ shows the XRD diffractograms obtained from the GPH(x)/CS:PVA membranes which are quite similar to each other irrespectively of the loading of GPH in the polymeric matrix. Figure $4 b$ also presents peaks at $19^{\circ}$ and $20^{\circ}$, which are attributed to the crystalline forms of PVA and CS, respectively, and whose intensities are dominated by the presence of GPH loading. The pattern of XRD plots corresponds to hydrated semicrystalline peaks, mainly due to hydrogen bonding between the CS and/or PVA chains. Hence, the interaction between the side chains of PVA and CS affects the physical properties of crystallinity and mechanical stability as a function of GPH loading. These results are in agreement with those obtained by García-Cruz et al. [25], who carried out studies on the role of the incorporation of 1.0 wt. \% GO within the polymeric matrix of CS:PVA.

Also, our XRD results are in accordance with those obtained by Feng et al. [14] and Yang et al. [11],

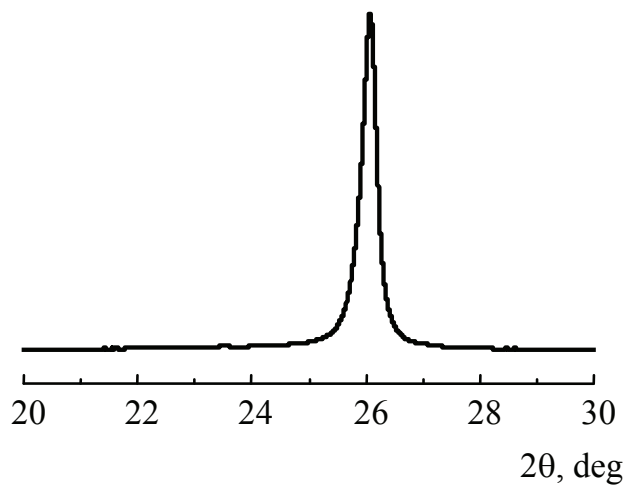

Fig. 3. XRD diffractogram of the GPH sample 


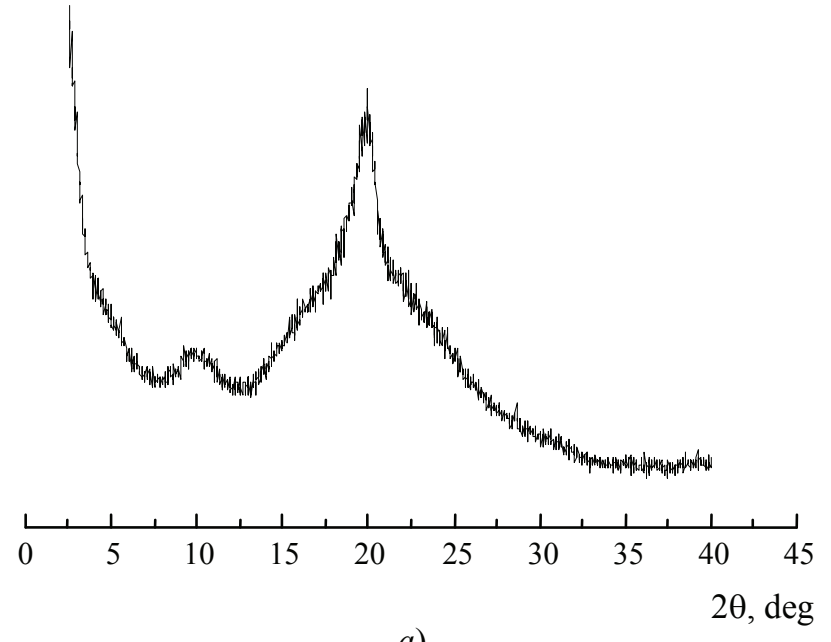

a)
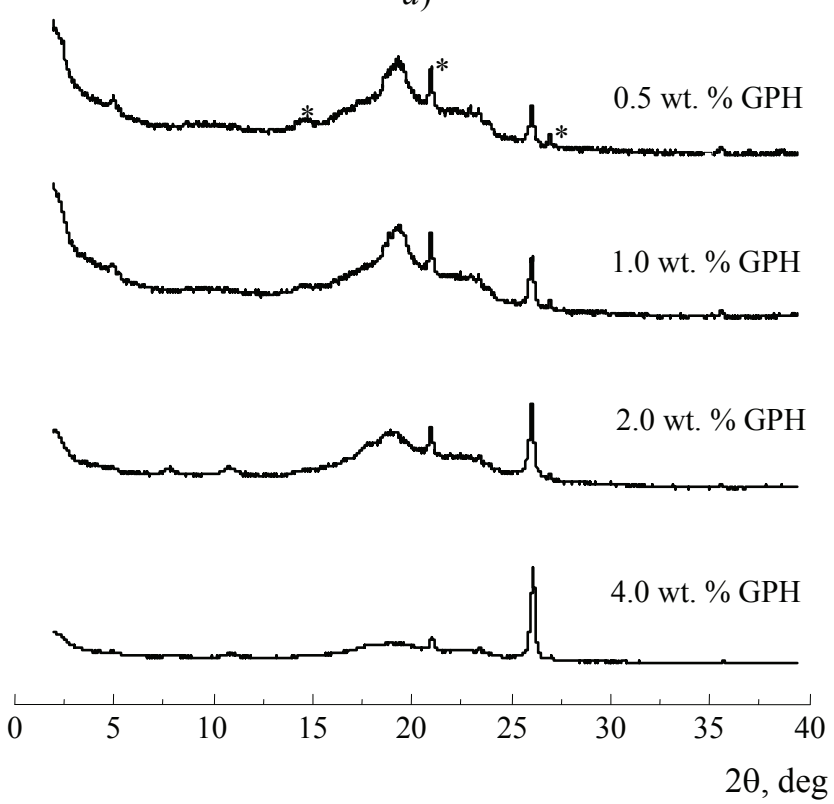

b)

Fig. 4. XRD diffractogram of the pristine CS:PVA membrane (a) and XRD diffractogram of GPH(x)/CS:PVA membranes prepared in this work $(b)$

who noticed that the addition of GPH and other GPH derivatives in a polymer matrix based on the CS and PVA mixture at a ratio of 10:90 CS:PVA, reduced the crystalline character compared to pure matrix membranes. On the other hand, all the GPH hybrid membrane samples analyzed in this wok exhibit a peak around $26.4^{\circ}$ corresponding to GPH nanoplatelets, as shown in Fig. 3. This peak intensity is more pronounced at higher GPH loadings, although the membrane leads gradually to a decrease in peak intensity at $2 \theta=10-12^{\circ}$; this attributed to a slight dispersion of the GPH in the CS:PVA membrane [31], no changes were observed for $L_{\mathrm{a}}$ and $L_{\mathrm{c}}$ values obtained from equation (3) with the concentration of GPH inside the CS:PVA polymeric matrix.

\section{Surface Chemistry}

X-ray photoelectron spectroscopy (XPS) is used to determine the functionalised groups of synthesized membranes. In addition, XPS technique provides information about the relative element content. XPS analysis on different doped membranes with different GPH percentages has fundamentally detected the presence of $\mathrm{C}, \mathrm{O}$ and $\mathrm{N}$, as expected from the chemical composition of the polymers of CS and PVA as well as the presence of GPH nanosheets. Table 1 compiles the bonding energies that appear in the XPS spectra, the relative atomic percentages and the assignment of the functional groups of the pristine GPH and different $\mathrm{GPH}(\mathrm{x}) / \mathrm{CS}:$ PVA membranes, with $\mathrm{x}=0.5,1.0,2.0$ and 4.0 wt. $\%$.

From Table 1, it is seen that the binding energy for the major functionalised groups appear to be similar for all membranes and hence XPS results are independent of the weight percentages of graphene used. The contribution corresponding to the lower binding energies $(\mathrm{C} 1 \mathrm{~s}, 284.6 \mathrm{eV})$ is mainly attributed to the presence of graphite or to $\mathrm{C}-\mathrm{C}$ bonds. The contribution at $285.4 \mathrm{eV}$ is assigned to the presence of aliphatic $\mathrm{Csp}^{3}$ carbons and $\mathrm{C}-\mathrm{H}$ terminal carbon atoms. The contribution occurring at a binding energy of about $286.5 \mathrm{eV}$ corresponds to the $\mathrm{C}-\mathrm{O}, \mathrm{C}-\mathrm{O}-\mathrm{C}$ or $\mathrm{C}-\mathrm{N}$ functional groups. Finally, the contribution associated with the binding energy of ca. $288 \mathrm{eV}$ is assigned to the presence of the functional groups $\mathrm{C}=\mathrm{O}, \mathrm{O}-\mathrm{C}-\mathrm{O}$ or $\mathrm{O}-\mathrm{C}=\mathrm{O}$. The determination of the relative atomic percentages of the $\mathrm{C} 1, \mathrm{C} 3$ and $\mathrm{C} 4$ peaks according to the $\mathrm{C} 1 /(\mathrm{C} 3+\mathrm{C} 4)$ ratio indicates that there is a higher concentration of polar functional groups on the membrane surface when the membrane is modified with a 4.0 wt. \% GPH. Interestingly, the membrane having a lower content of oxygenated functional groups corresponds to that doped with 1.0 wt. $\%$.

On the other hand, the $\mathrm{O} 1 \mathrm{~s}$ contribution of the XPS spectra revealed two fundamental peaks with binding energies around $531 \mathrm{eV}$, with assignment of functional groups such as $\mathrm{C}=\mathrm{O}$ and / or $\mathrm{OH}$, and another binding energy at around $532 \mathrm{eV}$, which was assigned to such as $-\mathrm{C}=\mathrm{O}$ and $/$ or $\mathrm{O}=\mathrm{C}-\mathrm{O}$. In addition, we considered the relative atomic percentage of $\mathrm{O} 1 \mathrm{~s}$ and $\mathrm{C}$ 1s core level energies associated with the total percentages of $\mathrm{O}$ and $\mathrm{C}$, respectively. The $\mathrm{C} / \mathrm{O}$ ratios were of $2.55,2.5$ and 2.33 for $0.5,2.0$ and 4.0 wt. \% $\mathrm{GPH}$, respectively. However, the CS:PVA polymeric matrix with $1.0 \mathrm{wt}$ \% GPH exhibits a $\mathrm{C} / \mathrm{O}$ ratio of 5.6, which is approximately twofold the values shown above, indicating that the contribution of the 
Assignment of the main spectral bands according to binding energies (BE)

in $\mathrm{eV}$ for CS:PVA modified graphene membranes. The values presented in parentheses correspond to the relative atomic percentages

\begin{tabular}{|c|c|c|c|c|c|c|}
\hline $\begin{array}{c}\text { Core energy } \\
\text { level and } \\
\text { peaks }\end{array}$ & GPH & $\begin{array}{l}\text { GPH(0.5)/ } \\
\text { CS:PVA }\end{array}$ & $\begin{array}{l}\text { GPH(1.0)/ } \\
\text { CS:PVA }\end{array}$ & $\begin{array}{l}\text { GPH(2.0)/ } \\
\text { CS:PVA }\end{array}$ & $\begin{array}{l}\text { GPH(4.0)/ } \\
\text { CS:PVA }\end{array}$ & $\begin{array}{l}\text { Functional } \\
\text { group } \\
\text { assignment }\end{array}$ \\
\hline \multicolumn{7}{|l|}{$\mathrm{C}_{1 \mathrm{~s}}$} \\
\hline $\mathrm{C} 1$ & $\begin{array}{l}284.58 \\
(71.65)\end{array}$ & $\begin{array}{l}284.56 \\
(34.22)\end{array}$ & $\begin{array}{l}284.58 \\
(39.99)\end{array}$ & $\begin{array}{l}284.56 \\
(26.87)\end{array}$ & $\begin{array}{l}284.6 \\
(21.51)\end{array}$ & $\begin{array}{c}\mathrm{C}-\mathrm{C} \\
\mathrm{C}-\text { graphite }\end{array}$ \\
\hline $\mathrm{C} 2$ & $\begin{array}{l}285.43 \\
(16.11)\end{array}$ & & $\begin{array}{l}285.35 \\
(25.91)\end{array}$ & $\begin{array}{l}285.56 \\
(7.69)\end{array}$ & $\begin{array}{l}285.4 \\
(9.06)\end{array}$ & $\begin{array}{c}\mathrm{Csp}^{3} \\
\text { aliphatic } \\
\mathrm{C}-\mathrm{H}\end{array}$ \\
\hline $\mathrm{C} 3$ & $\begin{array}{l}286.54 \\
(4.18)\end{array}$ & $\begin{array}{l}286.18 \\
(23.83)\end{array}$ & $\begin{array}{l}286.69 \\
(14.31)\end{array}$ & $\begin{array}{c}286.3 \\
(22.46)\end{array}$ & $\begin{array}{l}286.33 \\
(26.54)\end{array}$ & $\begin{array}{c}\mathrm{C}-\mathrm{O} \\
\mathrm{C}-\mathrm{O}-\mathrm{C} ; \mathrm{C}-\mathrm{N}\end{array}$ \\
\hline $\mathrm{C} 4$ & $\begin{array}{l}288.31 \\
(1.01)\end{array}$ & $\begin{array}{l}287.91 \\
(9.02)\end{array}$ & $\begin{array}{c}288.41 \\
(3.19)\end{array}$ & $\begin{array}{l}287.73 \\
(10.61)\end{array}$ & $\begin{array}{l}287.85 \\
(9.23)\end{array}$ & $\begin{array}{c}\mathrm{C}=\mathrm{O}, \\
\mathrm{O}-\mathrm{C}-\mathrm{O} \\
\mathrm{O}-\mathrm{C}=\mathrm{O}\end{array}$ \\
\hline $\begin{array}{c}\mathrm{C} \\
\text { (total wt. \%) } \\
\end{array}$ & 93.0 & 67.07 & 83.40 & 67.63 & 65.93 & \\
\hline \multirow[t]{2}{*}{$\mathbf{O}_{1 \mathrm{~s}}$} & $\begin{array}{l}531.79 \\
(4.77)\end{array}$ & $\begin{array}{l}531.1 \\
(7.24)\end{array}$ & $\begin{array}{l}531.01 \\
(4.92)\end{array}$ & $\begin{array}{l}531.14 \\
(2.84)\end{array}$ & $\begin{array}{l}531.27 \\
(3.35)\end{array}$ & $\mathrm{C}=\mathrm{O} ; \mathrm{OH}^{-}$ \\
\hline & $\begin{array}{l}533.18 \\
(2.15)\end{array}$ & $\begin{array}{l}532.38 \\
(19.04)\end{array}$ & $\begin{array}{l}532.16 \\
(9.85)\end{array}$ & $\begin{array}{l}532.63 \\
(24.29)\end{array}$ & $\begin{array}{l}532.69 \\
(24.86)\end{array}$ & $\begin{array}{c}-\mathrm{C}=\mathrm{O} \\
\mathrm{O}=\mathrm{C}-\mathrm{O}\end{array}$ \\
\hline $\begin{array}{c}0 \\
\text { (total wt. \%) } \\
\end{array}$ & 6.32 & 26.28 & 14.77 & 27.13 & 28.21 & \\
\hline \multirow[t]{2}{*}{$\mathbf{N}_{1 \mathrm{~s}}$} & $\begin{array}{l}399.43 \\
(0.14)\end{array}$ & $\begin{array}{l}399.31 \\
(6.32)\end{array}$ & $\begin{array}{l}399.15 \\
(1.83)\end{array}$ & $\begin{array}{l}399.23 \\
(4.81)\end{array}$ & $\begin{array}{l}399.31 \\
(4.83)\end{array}$ & $\begin{array}{l}-\mathrm{NH}_{2} \\
-\mathrm{NH}-\end{array}$ \\
\hline & & $\begin{array}{l}401.34 \\
(0.33)\end{array}$ & & $\begin{array}{l}401.28 \\
(0.43)\end{array}$ & $\begin{array}{l}401.4 \\
(0.62)\end{array}$ & $\mathrm{C}-\mathrm{N} ;-\mathrm{NH}_{3}^{+}$ \\
\hline $\begin{array}{c}\mathrm{N} \\
\text { (total wt. \%) }\end{array}$ & 0.14 & 6.65 & 1.83 & 5.24 & 5.45 & \\
\hline
\end{tabular}

oxygenated functionalised groups is lower for the GPH(1.0)/CS:PVA membrane.

Table 1 also shows the $\mathrm{N} 1 \mathrm{~s}$ core level energy revealing a binding energy at around $399 \mathrm{eV}$, attributed to the presence of $-\mathrm{NH}_{2}$ and $-\mathrm{NH}-$ that can be extracted from the surface of the chitosan. Morever, the evolution of the relative atomic concentration of $\mathrm{N}$ on the membrane surface as a function of wt. \%. is worth noticing. In this regard, GPH(1.0)/CS:PVA membrane presented the lowest value of $1.83 \mathrm{wt} \%$ of atomic nitrogen, corroborating the more hydrophobic character of the above membrane with 1.0 wt. \% of GPH. On the other hand, in some cases, the $\mathrm{N} 1 \mathrm{~s}$ signal can also be observed with a binding energy at $401 \mathrm{eV}$ which is associated with the presence of $\mathrm{C}-\mathrm{N}$ and / or $-\mathrm{NH}_{3}{ }^{+}$functionalised groups.

\section{Thermogravimetric Analysis}

Different GPH/CS:PVA membranes were analysed by TGA to get the respective thermogravimetric curves (TG) (Fig. $5 a$ ) and the plots regarding the differential 
Weight, wt. \%

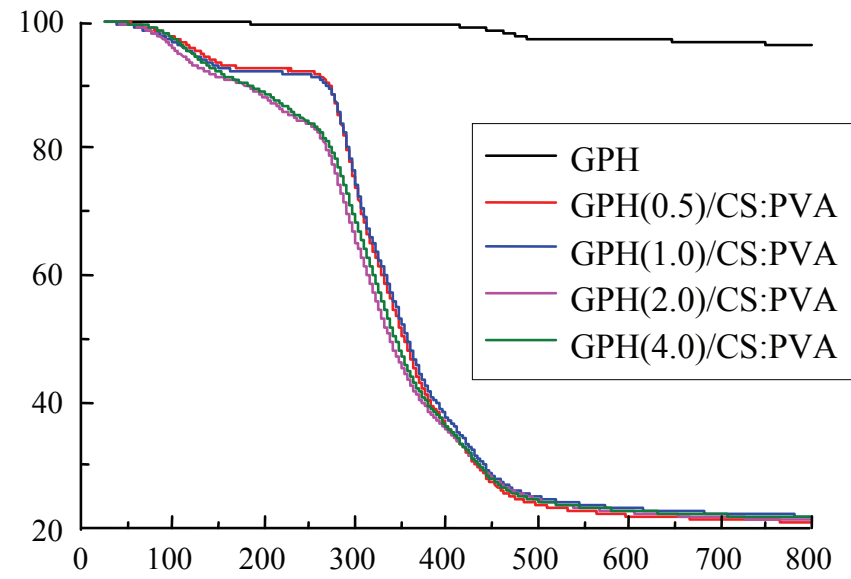

a)

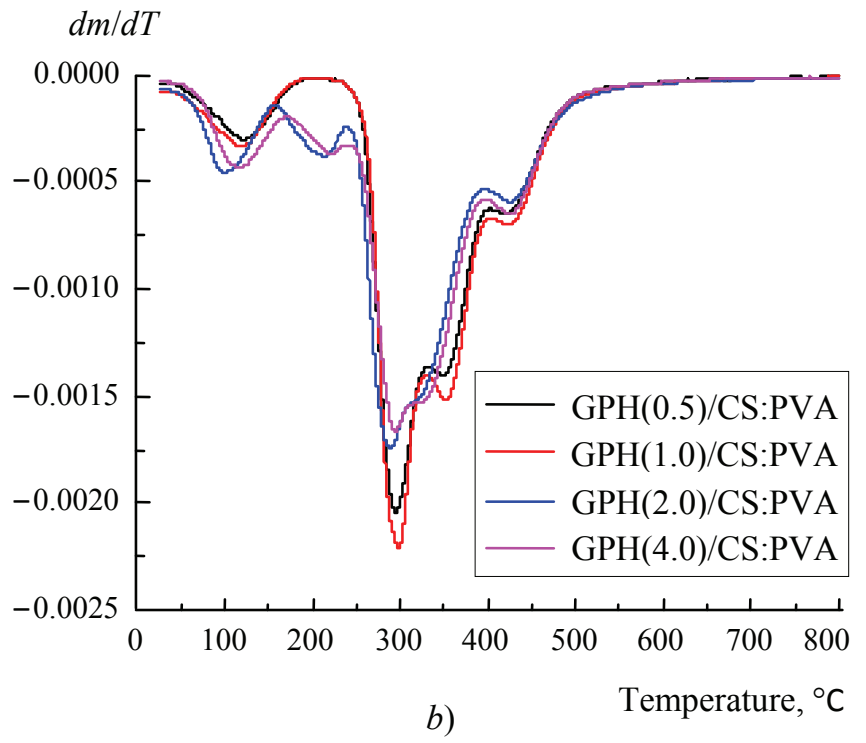

Fig. 5. TGA of GPH(x)/CS:PVA membranes and GPH used in this study (a); DTA of GPH(x)/CS:PVA membranes (b)

thermal analysis (DTA) (Fig. 5 b). TG plots showed three perfectly differentiated stages. As it can be seen in Fig. $5 a$, an endothermic effect is firstly produced around $100{ }^{\circ} \mathrm{C}$ with a polymer weight loss of $10-15$ wt. $\%$, which was attributed to the release of the moisture preferentially absorbed by the polymer CS:PVA matrix. The next step is attributed to the polymer decomposition and also to the elimination of volatile products. The third stage is mostly related to the combustion of the membrane. According to the results shown in Fig. $5 a$, the thermal stability has the following sequence:

$$
\begin{aligned}
& \mathrm{GPH}(0.5) / \mathrm{CS}: \mathrm{PVA}=\mathrm{GPH}(1.0) / \mathrm{CS}: \mathrm{PVA}> \\
> & \mathrm{GPH}(2.0) / \mathrm{CS}: \mathrm{PVA}>\mathrm{GPH}(4.0) / \mathrm{CS}: \mathrm{PVA} .
\end{aligned}
$$

This would indicate that the lower percentages of 0.5 and 1.0 wt. \% GPH material into the polymer matrix lead to the improvement of the thermal stability by about $20^{\circ} \mathrm{C}$. In contrast, a detrimental effect on the thermal stability was observed for 2.0 and 4.0 GPH wt. \%.

Similarly, differential thermal analysis (DTA) curves show changes in the intensity of exothermic / endothermic peaks, and their peak positions are slightly influenced by the GPH content within the membrane matrix. As shown in Fig. $5 b$, DTA curves exhibit a broad endothermic peak around $100^{\circ} \mathrm{C}$ which is related to the evaporation of the water, i.e., WC present in the membrane. The peak appearing at temperature ranging between 250 and $350{ }^{\circ} \mathrm{C}$ is referred to the decomposition or breaking down of the crosslinking of the CS:PVA polymeric matrix, with a major weight loss of 4.0 wt. \%. These results are similar to those shown for grapheme-modified chitosan-based polymers [31]. Moreover, the peak found between 350 and $400{ }^{\circ} \mathrm{C}$ is uncertain and also observed in the literature [31]. That could be intrinsically related to the peak found between 250 and $350{ }^{\circ} \mathrm{C}$. Alike TGA plots, the peak present between 400 and $450{ }^{\circ} \mathrm{C}$ would be associated with the decomposition of the polymeric matrix. As the GPH loading increases in the matrix, the thermal stability improves due to hydrophilic and electrostatic interactions between CS and GPH.

\section{Water Content}

Table 2 compiles the values of WC for the GPH(x)/CS:PVA membranes. Water Content values decrease with increasing GPH loading inside the CS:PVA matrix due to the hydrophobic character inferring the carbonaceous additive, thus providing a lower water absorption capacity inside the membrane. Nonetheless, a much higher GPH loading inside the CS:PVA polymeric membrane reverses the above trend thereby retrieving quickly the value obtained for pristine CS:PVA membrane.

Table 2

Water content and mean specific ionic conductivity $\sigma_{m}$ of GPH(x)/CS:PVA membranes

\begin{tabular}{ccc}
\hline Membrane & WC, $\%$ & $\sigma_{\mathrm{m}}, \mathrm{mS} \cdot \mathrm{cm}^{-1}$ \\
\hline CS:PVA & 23.11 & $0.1520 \pm 0.0011 \mathrm{SD}(N=3)$ \\
GPH(0.5)/CS:PVA & 18.82 & $0.1700 \pm 0.0003 \mathrm{SD}(N=3)$ \\
$\mathrm{GPH}(1.0) / \mathrm{CS}: \mathrm{PVA}$ & 19.97 & $0.2700 \pm 0.0340 \mathrm{SD}(N=6)$ \\
$\mathrm{GPH}(2.0) / \mathrm{CS}: \mathrm{PVA}$ & 24.05 & $0.1580 \pm 0.0030 \mathrm{SD}(N=6)$ \\
$\mathrm{GPH}(4.0) / \mathrm{CS}: \mathrm{PVA}$ & 25.25 & $0.1720 \pm 0.0006(N=3)$ \\
\hline
\end{tabular}

SD: Standard deviation. 
A slight decrease in WC value with low GPH loading in the anion exchange membranes also correlates with the slight loss of crystallinity or the degree loss of crosslinking of the polymeric matrix, as shown by the XRD experiments in Fig. $4 b$; a decrease in WC is related to the slight loss of crystallinity, so the interaction of oxygen-rich hydrophilic surface of $\mathrm{CS}: \mathrm{PVA}$ polymeric membrane and graphene sheets is becoming much stronger with moderate GPH loading, thereby reducing the $\mathrm{WC}$ value. Furthermore, the homogeneity ammelioration of the membrane surface with GPH loading could be related to the more hydrophobic character of the membrane, and hence its chemistry surface of the membrane. We speculate, nonetheless, that the higher WC values for GPH loadings of 2.0 and $4.0 \mathrm{wt} \%$ is a matter of crosslinking changes and electrostatic interactions between the polymer and GPH sheets.

\section{Specific Ionic Conductivity}

Figure 6 shows a comparison of the Nyquist plots for different measurements performed in this work with increasing GPH loading. From the EIS experiments performed using a two electrode Swagelok cell, the mean specific ionic conductivity values of the CS:PVA membranes are collected in Table 2.

Ion exchange membranes exhibit electrical properties that can be modelled as a sum of impedances in an equivalent circuit as depicted in Fig. 7. Such equivalent circuit is adscribed to an ion exchange membrane placed between two electrodes located in electrochemical cell.

The specific ionic conductivity of the $\mathrm{GPH}(\mathrm{x}) / \mathrm{CS}$ :PVA membranes along with the pristine polymer was calculated by equation (3). Table 2 compiles the mean ionic conductivity $\left(\sigma_{\mathrm{m}}\right)$ which

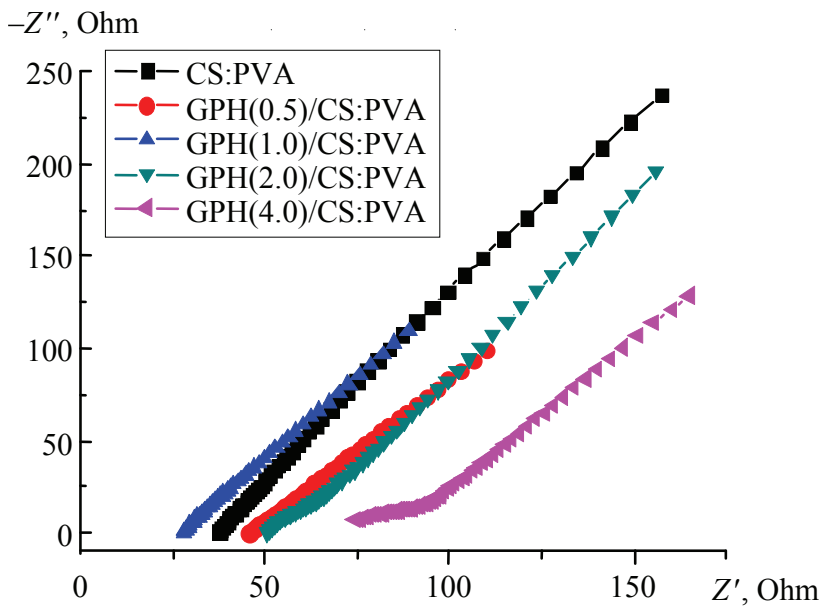

Fig. 6. Nyquist plot of CS:PVA and GPH(x)/CS:PVA membranes

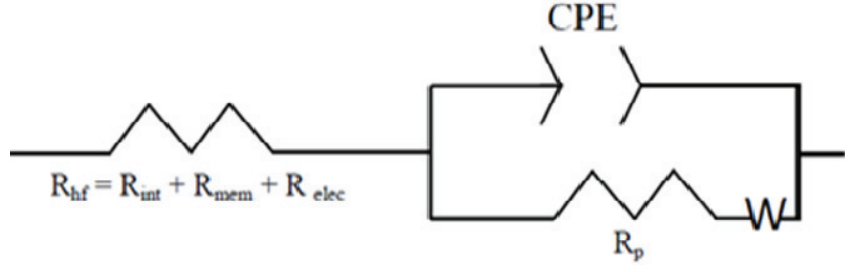

Fig. 7. Equivalent electrical circuit for an ion-exchange membrane used to fit the impedance spectra $[28,33]$. $\mathrm{W}$ is the Warburg element or diffusive element; $\mathrm{R}_{\mathrm{hf}}$ is the resistance at high frequency which corresponds to the combination of internal resistance $R_{\text {int }}$ (the resistance between the electrode and membrane surfaces, namely also the free water surface), the electrode resistance, $R_{\text {elec, }}$, and $R_{\text {mem }}$ as the resistance of the polymeric membrane [34]. Finally, $\mathrm{R}_{\mathrm{p}}$ denotes the polarization resistance or the charge transfer resistance, and CPE is the constant phase element. CPE is associated with a surface non-homogeneity that provides a non-uniform distribution of current density over the electrode [35]

corresponds to the average of three measurements. The thickness used for the calculation of $\sigma_{\mathrm{m}}$ was the average thickness measured at three different points of the membrane.

The specific ionic conductivities of the $\mathrm{GPH}(\mathrm{x}) / \mathrm{CS}$ :PVA membranes along with the pristine polymer were calculated by equation (2). Table 2 compiles the mean ionic conductivity $\sigma_{\mathrm{m}}$ which corresponds to the average of three measurements. The thickness used for the calculation of $\sigma_{\mathrm{m}}$ was the average thickness measured at three different points of the membrane. As seen in Table 2, the GPH(1.0)/CS:PVA membrane showed the highest conductivity with a value of $0.270 \mathrm{mS} \mathrm{cm}$ followed by the GPH (0.5)/CS:PVA and GPH(4.0)/CS:PVA, and showing the lowest value for the GPH(2.0)/CS:PVA membrane along with the pristine one. Higher GPH loadings did not reveal an improvement in ionic conductivity values, probably attributed to a much stronger GPH electrostatic interaction with the polymeric matrix, and thereby likely hampering the $\mathrm{OH}^{-}$mobility through the membrane. In contrast, lower GPH loading allowed a higher dispersion of the GPH layers within the polymer matrix, being in this regard the percentage of 1.0 wt. \% the most optimum value found. Similar results were obtained by Yang, et al. [11], who describe a remarkable increase in ionic conductivity of the anion exchange membrane using a CS:PVA of $10: 90$ wt. \% ratio when doped with graphene and sulphonated modified graphenes. Therefore, the doping of polymer matrices with GPH sheets improves the electrochemical conductance, even though we found a mismatching in conductances values between our pristine CS:PVA membrane with a 50 to 50 ratio 
of CS:PVA in wt. $\%\left(0.152 \mathrm{mS} \cdot \mathrm{cm}^{-1}\right)$ and that presented by Yang and col. [11] of 10 to 90 ratio in wt. \% $\left(0.024 \mathrm{~S} \cdot \mathrm{cm}^{-1}\right)$ at $298 \mathrm{~K}$. Finally, it is important to note that the incorporation of GPH provided just a slight loss of CS:PVA crystallinity, as shown in XRD diffractograms. This would indicate that the almost retention of the polymeric crystallinity can be responsible for small improvement in conductance of $\mathrm{OH}^{-i}$ ions through its polymeric structure.

\section{Conclusion}

The morphology of the GPH(x)/CS:PVA membranes is dominated by GPH loading. The crystallinity decreases slightly as the percentage of GPH increases to a value of 4.0 wt. \%. However, an increase of GPH does not even cause a complete loss of the crystallinity of the pristine polymeric blend. Nonetheless, the presence of grapheme sheets determines the semi-crystalline behavior of the membrane, and hence the thermal and electrochemical conductance properties. For example, thermal analysis of the $\mathrm{GPH}(0.5) / \mathrm{CS}: \mathrm{PVA}$ membranes reveals a beneficial effect on the thermal stability related to the decomposition of the functional groups of the polymer backbone, although this is only manifested by low GPH loadings. With regards to the specific ionic conductivity of the hydroxyl anion, a remarkable improvement could be expected with increasing in GPH wt. \%, as other authors have demonstrated in the literature [11]. However, the nature, textural and surface chemistry properties of the selected GPH are determinant variables when extrapolating or even reproducing part of the results published in the literature. Even although the most optimal percentage of GPH found corresponds to $1.0 \mathrm{wt} \%$, these results should be subjected to scaling study of the membrane manufacturing process at laboratory and its use in electrochemical devices.

\section{Acknowledgments}

The authors thank the Ministerio de Economía y Competitividad for its financial support (CTQ201348280-C3-3-R). Also, Jesús Iniesta gives thanks to Relaciones Internacionales for the PPI grant suppoted by the University of Alicante, Spain.

\section{References}

1. Risen, J.W. Applications of ionomers, in: S. Schuck (Ed.) Ionomers Characterization, Theory and Applications. 1996.
2. Hideo, K.T. K., Shimizu, H. Ion exchange membranes, in: K. Dorfner (Ed.) Ion Exchangers. Berlin, 1991.

3. Shaari, N., Kamarudin, S.K. Chitosan and alginate types of bio-membrane in fuel cell application: An overview. Journal of Power Sources, 2015, 289, pp. 71-80.

4. Huang, A.B., Xia, C.Y., Xiao, C.B., Zhuang, L. Composite anion exchange membrane for alkaline direct methanol fuel cell: Structural and electrochemical characterization. Journal of Applied Polymer Science, 2006, 100, pp. 2248-2251.

5. Merle, G., Wessling, M., Nijmeijer, K. Anion exchange membranes for alkaline fuel cells: A review. Journal of Membrane Science, 2011, 377, pp. 1-35.

6. Maiti, J., Kakati, N., Lee, S.H., Jee, S.H., Viswanathan, B., Yoon, Y.S. Where do poly(vinyl alcohol) based membranes stand in relation to Nafion ${ }^{\circledR}$ for direct methanol fuel cell applications? Journal of Power Sources, 2012, 216, pp. 48-66.

7. Xion,g Y., Liu, Q.L., Zhang, Q.G., Zhu, A.M. Synthesis and characterization of cross-linked quaternized poly(vinyl alcohol)/chitosan composite anion exchange membranes for fuel cells. Journal of Power Sources, 2008, 183, pp. 447-453.

8. Wu, C., Wu, Y., Xu, T., Fu, Y. Novel anionexchange organic-inorganic hybrid membranes prepared through sol-gel reaction and UV/thermal curing. Journal of Applied Polymer Science, 2008, 107, pp. 1865-1871.

9. Kim, D. J., Jo, M. J., Nam, S.Y. A review of polymer-nanocomposite electrolyte membranes for fuel cell application. Journal of Industrial and Engineering Chemistry, 2015, 21, pp. 36-52.

10. Zuo, G., Wan, Y., Wang, L., Liu, C., He, F., Luo, H. Synthesis and characterization of laminated hydroxyapatite/chitosan nanocomposites. Materials Letters, 2010, 64, pp. 2126-2128.

11. Yang, J.-M., Wang, S. A. Preparation of graphene-based poly(vinyl alcohol)/chitosan nanocomposites membrane for alkaline solid electrolytes membrane. Journal of Membrane Science, 2015, 477, pp. 49-57.

12. Shao, L., Chang, X.J., Zhang, Y.L., Huang, Y.F., Yao, Y.H., Guo, Z.H. Graphene oxide cross-linked chitosan nanocomposite membrane. Applied Surface Science, 2013, 280, pp. 989-992.

13. Bao, C., Guo, Y., Song, L., Hu, Y. Poly(vinyl alcohol) nanocomposites based on graphene and graphite oxide: a comparative investigation of property and mechanism. Journal of Materials Chemistry, 2011, 21, pp. 13942-13950. 
14. Feng, X.M., Wang, X., Xing, W.Y., Yu, B., Song, L., Hu, Y. Simultaneous Reduction and Surface Functionalization of Graphene Oxide by Chitosan and Their Synergistic Reinforcing Effects in PVA Films. Industrial \& Engineering Chemistry Research, 2013, 52, pp. 12906-12914.

15. Ma, J., Sahai, Y. Chitosan biopolymer for fuel cell applications. Carbohydrate Polymers, 2013, 92, pp. 955-975.

16. Xu, D., Hein, S., Wang, K. Chitosan membrane in separation applications. Materials Science and Technology, 2008, 24, pp. 1076-1087.

17. Thakur, V.K., Voicu, S.I. Recent advances in cellulose and chitosan based membranes for water purification: A concise review. Carbohydrate Polymers, 2016, 146, pp. 148-165.

18. Voicu, S.I., Muhulet, A., Antoniac, I.V., Corobea, M. S. Cellulose Derivatives Based Membranes for Biomedical Applications. Key Engineering Materials, 2012, 638, pp. 27-30.

19. Yang, C.C., Lee, Y.J., Chiu, S.J., Lee, K.T., Chien, W.C., Lin, C.T., Huang, C.A. Preparation of a PVA/HAP composite polymer membrane for a direct ethanol fuel cell (DEFC). Journal of Applied Electrochemistry, 2008, 38, pp. 1329-1337.

20. Masanao, W.P.I. Novel Biopolymer Composite Membrane Involved with Selective Mass Transfer and Excellent Water Permeability, in: R.Y. Ning (Ed.) Advancing Desalination, InTech.

21. Krajewska, B. Diffusional properties of chitosan hydrogel membranes. Journal of Chemical Technology and Biotechnology, 2001, 76, pp. 636-642.

22. De Silva, R.T., Pasbakhsh, P., Goh, K.L., Chai, S.P., Ismail, H. Physico-chemical characterisation of chitosan/halloysite composite membranes. Polymer Testing, 2013, 32, pp. 265-271.

23. Zhu, Y.X., Xia, S.S., Liu, G.P., Jin, W.Q. Preparation of ceramic-supported poly(vinyl alcohol)chitosan composite membranes and their applications in pervaporation dehydration of organic/water mixtures. Journal of Membrane Science, 2010, 349, pp. 341-348.

24. Zhang, Y., Cui, Z., Liu, C., Xing, W., Zhang, J. Implantation of Nafion ${ }^{\circledR}$ ionomer into polyvinyl alcohol/chitosan composites to form novel protonconducting membranes for direct methanol fuel cells. Journal of Power Sources, 2009, 194, pp. 730-736.

25. García-Cruz, L., Casado-Coterillo, C., Irabien, A., Montiel, V., Iniesta, J. High performance of alkaline anion-exchange membranes based on Chitosan/Poly(vinyl) alcohol doped with graphene oxide for the electrooxidation of primary alcohols. C Journal of Carbon Research, 2016, 2, pp. 10-28.

26. Franck-Lacaze, L., Sistat, P., Huguet, P. Determination of the pKa of poly (4-vinylpyridine)based weak anion exchange membranes for the investigation of the side proton leakage. Journal of Membrane Science, 2009, 326, pp. 650-658.

27. Garcia-Cruz, L., Casado-Coterillo, C., Iniesta, J., Montiel, V., Irabien, A. Chitosan:poly (vinyl) alcohol composite alkaline membrane incorporating organic ionomers and layered silicate materials into a PEM electrochemical reactor. Journal of Membrane Science, 2016, 498, pp. 395-407.

28. Garcia-Cruz, L., Casado-Coterillo, C., Iniesta, J., Montiel, V., Irabien, A. Preparation and characterization of novel chitosan-based mixed matrix membranes resistant in alkaline media. Journal of Applied Polymer Science, 2015, 132, pp. 42240-42249.

29. Jeong, H.K., Jin, M.H., So, K.P., Lim, S.C., Lee, Y.H. Tailoring the characteristics of graphite oxides by different oxidation times. Journal of Physics D: Applied Physics, 2009, 42, pp. 1-6.

30. Choi B.G., Huh Y.S., Park Y.C., Jung D.H., Hong W.H., Park H. Enhanced transport properties in polymer electrolyte composite membranes with graphene oxide sheets. Carbon, 2012, 50, pp. 53955402.

31. Dharupaneedi, S.P., Anjanapura, R.V., Han, J.M., Aminabhavi, T.M. Functionalized Graphene Sheets Embedded in Chitosan Nanocomposite Membranes for Ethanol and Isopropanol Dehydration via Pervaporation. Industrial \& Engineering Chemistry Research, 2014, 53, pp. 14474-14484.

32. Warren, E., Bodenstein, P. The diffraction pattern of fine particle carbon blacks. Acta Crystallographica, 1965, 18, pp. 282-286.

33. Yun, S.H., Shin, S.H., Lee, J.Y., Seo, S.J., Oh, S.H., Choi, Y.W., Moon, S.H. Effect of pressure on through-plane proton conductivity of polymer electrolyte membranes. Journal of Membrane Science, 2012, 417-418, pp. 210-216.

34. Asghari, S., Mokmeli, A., Samavati, M. Study of PEM fuel cell performance by electrochemical impedance spectroscopy. International Journal of Hydrogen Energy, 2010, 35, pp. 9283-9290.

35. Rezaei, Niya, S.M., Hoorfar, M. Study of proton exchange membrane fuel cells using electrochemical impedance spectroscopy technique A review. Journal of Power Sources, 2013, 240, pp. 281-293. 